\title{
1. Human values and the conservation of wild species: an overview
}

\subsection{INTRODUCTION}

Human valuation of other species has major implications for the conservation of biodiversity. This is because this valuation influences the intentions and actions of humans to conserve other species and their failure to do so. In the modern era, human activities and behaviours are the prime determinant of the extinction of other species, whereas in the past, their mass extinctions have been caused by natural environmental calamities. ${ }^{1}$ Therefore, the investigation of human values and behaviours in relation to the conservation of biological resources is central to the study of contemporary biodiversity loss. This book has been written to advance this investigation.

Nevertheless, such a study is challenging because the connections between human values and biodiversity conservation are complex. For example, different individuals frequently hold conflicting values; these values are not always stable (they can vary with the passage of time) and they may be based on faulty or limited knowledge. In fact, limited knowledge is a serious problem given the existence of bounded rationality. Furthermore, for several reasons, held values may not be translated into corresponding conservation behaviours. For example, institutional failures of various kinds may occur. These include free-riding in large group situations, and the presence of transaction costs that hinder optimizing behaviour by groups (Tisdell, 1996, Chapter 8). Institutional biases may also occur (for instance, of the type considered in Chapter 7 of this book) and can result in collective funding for the conservation of different wildlife species deviating from levels desired by members of the public. Furthermore, individuals may fail to follow through on their once intended conservation actions because of the presence of drop-off or erosion effects (see the next chapter and Chapter 3).

This book focuses mainly on the study of stated values and preferences of individuals and their implications for the conservation and survival of wild species. This subject is investigated by using data obtained from surveys and case studies, relying mostly (but not entirely) on empirical information collected in Australia. Particular attention is given to determining the factors 
that influence the stated willingness of those individuals surveyed to pay for the conservation of different wildlife species, taking into account variations in the attributes or characteristics of these species as well as the knowledge that individuals have of them. In addition, the extent to which individuals support the survival of different wildlife species (and why they do so) are given special consideration. Support of individuals for the survival of species is found to differ from the extent to which they are willing to contribute funds for their conservation. This is because willingness to fund the conservation of a species depends on how endangered the survival of the species is. General relationships are derived from the empirical results obtained.

An additional aspect studied is the stated extent and nature of support given by members of the public for the use of wildlife species generally, including their sustainable use and their commercial use. Furthermore, results from a more specialized study of public attitudes to both the commercial use of wild species and to their subsistence use by Indigenous communities are reported and analysed. This is an important issue because both the United Nations Convention on Biological Diversity, which came into force in 1993 (see, for example, Article 11), and the International Union for Conservation of Nature - IUCN (see IUCN-UNEP-WWF, 1991) suggest that the use of wildlife species can provide positive incentives for the conservation of biodiversity. However, irrespective of the merit of this view, if the public does not support sustainable use policies they are unlikely to succeed. Therefore, in this book, public attitudes towards the harvest of particular species are determined (for example, towards the harvesting of hawksbill turtles in Chapter 8, and of saltwater crocodiles in Chapter 9) and for a range of species (for instance, in Chapters 15 and 16). The results are analysed and general conclusions are derived from these.

The remainder of this chapter develops as follows: first, there is a broad discussion of issues involved in determining the economic value of wild species and a general consideration of the influences on public support for their conservation and survival. This coverage is a prelude to the next chapter, which also belongs to Part I. Overviews of Parts II and III are then presented. Concluding comments follow.

\subsection{GENERAL ISSUES INVOLVED IN DETERMINING THE (ECONOMIC) VALUE OF WILD SPECIES AND SUPPORT FOR THEIR CONSERVATION AND SURVIVAL}

Although conceptual issues involving the valuation of wildlife species and support for their conservation and survival are analysed in detail in the 
next chapter, preliminary observations are in order here. It is now widely recognized that the economic value of most environmental commodities, including wildlife species, consists of their non-use values as well as their use values. Furthermore, use values of wildlife often consist of a consumptive and a non-consumptive component. The relative importance of these components tends to alter as the stage of economic development of a community changes. For example, the value of the consumptive component of wildlife species usually declines as a society transits from being one based on hunting and gathering to one that becomes based on agriculture, manufacturing and the supply of services. Furthermore, the value of the non-consumptive use of wildlife and its non-use economic value tend to increase with economic development. ${ }^{2}$ Both these components of the total economic value of wildlife species appear to be positively related to income levels and levels of education in society.

The main portion of the economic value of most wildlife species evaluated in this book consists of their non-use value plus their nonconsumptive use value. Nevertheless, some of the wild species investigated have significant consumptive uses or material use (as well as non-material values), such as the saltwater crocodile and the red kangaroo.

Changes have occurred in economic thought about what determines economic value. These changes may reflect alterations in the weights societies place on the different components of economic value as a result of their economic development. ${ }^{3}$ For instance, Karl Marx (1818-83) regarded only the supply of material goods to be productive and, therefore, of economic value. Activities producing services, such as tourism, were regarded by Marx as unproductive and, therefore, of no economic value.

This emphasis on material (tangible) output as a source of economic value, however, changed when some members of the Austrian School of Economics (for example, Carl Menger, 1840-1921) began to argue that the economic value of commodities depends on what individuals demand. This approach, described as the subjective theory of value (Anon, 2013c), recognized that commodities having an intangible nature could have economic value. This modern approach to economic value has been well expressed by Robbins (1937). For Robbins, the purpose of economics is to search for means to ensure that scarce resources are administered or managed so as to satisfy (to the maximum extent possible) human desires for commodities. According to this approach, it does not matter whether these desires are for physical attributes of commodities or not. Therefore, given this subjective approach to economic valuation, non-use values of wildlife and their non-consumptive use values should all be taken into account in the economic valuation of wildlife species. Whether or not the current frameworks for assessing the total 
economic valuation (TEV) of wildlife species do this adequately will be addressed in the next chapter.

Not everyone considers the TEV approach to valuing wildlife species to be acceptable. Those opposed to its use believe it to be too anthropocentric. They favour approaches based on a different set of ethics. For example, Leopold $(1933,1966)$ rejects this human-centred approach to the conservation of nature and adopts a 'land ethic'. He argues that humankind has a moral obligation to protect whole ecological communities, even species (such as wolves) within such communities that are regarded by many as serious pests. Sagoff (1996) expresses a similar view about anthropocentric bias. He claims that humans have a moral responsibility to protect biodiversity and conserve all species independently of human desires. In fact, it seems from the survey results reported in this book that there is considerable community support for this ethic because many respondents stated that all wildlife species have a right to exist.

Nevertheless, it is probable that most individuals base their valuation of other species on a combination of anthropocentric and ecocentric values. Even those individuals who are sympathetic to the survival of most other species may not favour the survival of all. For example, few if any are likely to favour the survival of bacteria and viruses causing diseases in humans. Would, for example, Sagoff object to the eradication of organisms causing smallpox or poliomyelitis?

In the next chapter, the adequacy of standard economic frameworks for specifying the TEV of wildlife species are discussed and the theoretical relationships of TEV (and its components) to the level of the population of a species are explored. Particular attention is given to this relationship for non-use values. It is also demonstrated that the willingness to pay (WTP) (contribute funds) for the conservation of a species does not measure its economic value nor does it indicate how much the survival of species is desired or valued compared to other species. Furthermore, this chapter outlines the pitfalls of relying on stated preference measures of support for the conservation and survival of wildlife species. Some of these pitfalls have received inadequate attention in the literature, such as reasons for the occurrence of a drop-off or erosion effect in values and behaviours. Discussions of hypothetical bias do not adequately cover the matter, as will be apparent from the exposition in Chapter 2. Also, the effectiveness and limitations of relying on the use of wildlife species as an incentive for biodiversity conservation are examined in Chapter 2.

Overviews of Parts II and III of this book follow. Part II concentrates on aspects of individuals' willingness to pay for the conservation of individual species, and the extent to which individuals support the survival of these species. In addition, attitudes to the commercial use of some individual 
species are reported and analysed. Policies adopted for the use of saltwater crocodiles and their effectiveness in conserving this species are given detailed coverage. Part III focuses on similar phenomena but considers the simultaneous conservation and potential use of several wildlife species. It enables some important general relationships to be established.

\subsection{VALUES AND THE CONSERVATION OF INDIVIDUAL SPECIES AND THEIR SUSTAINABLE USE: AN OVERVIEW OF PART II}

Chapter 3 explores how the experiences of ecotourists can alter their stated willingness to contribute financially to the conservation of wild species (in this case turtles) and alter their other intended conservation behaviours. Statements by visitors following their visit to the Mon Repos turtle rookery in Queensland provide evidence that this visit increased the amount they were willing to donate on average for conservation of marine turtles. Furthermore, according to the statements made by visitors, it increased their desire to adopt behaviours favourable to the conservation of sea turtles.

It is found that the amount visitors (those sampled following their visit) to Mon Repos said they are willing to contribute to the conservation of sea turtles increased with their level of education and their level of income. It was also higher if they actually made a donation for turtle conservation while at Mon Repos. The sampled visitors reported that they were more likely to adopt behaviours favouring the conservation of marine turtles if they saw turtles or their hatchlings during their visit, if they reported that their visit was informative, and if they said that, as a result of their visit to Mon Repos, they received extra (new) information about threats to sea turtles or about their biology. Both information provision and the nature of the (emotional) experiences of visitors to Mon Repos turtle rookery influenced their intended conservation behaviours.

The results suggest that ecotourists' experiences, such as those obtained at Mon Repos turtle rookery, can be very effective in developing behaviours favouring the conservation of wild species. Nevertheless, caution is required. The effectiveness of such experiences in developing proconservation behaviours is likely to be exaggerated when ecotourists are surveyed not long after their experience, as was so in the case of visitors to the Mon Repos turtle rookery. This is because with the passage of time the behavioural intentions of those having such experiences may not be sustained. A drop-off or erosion effect is likely, which results in failure to act fully on stated conservation intentions elicited soon after an ecotourism 
experience. In fact, contingent valuation measures (and other forms of stated environmental values and preferences) are all subject to an erosion effect as time passes (Tisdell et al., 2008).

The economics of conserving the Asian elephant in Sri Lanka is the subject of Chapter 4. It is hypothesized that the long-term survival of the Asian elephant in Sri Lanka depends on elephants being able to utilize land (particularly farmland) outside protected areas. The available evidence indicates that no national park in Sri Lanka is large enough to support, in the long term, a minimum viable population of elephants. It is hypothesized that farm households will be more tolerant of elephants using their land if they are fully compensated for damage caused by elephants. Consequently, the use of farmland by elephants will help to conserve elephants in Sri Lanka.

Urban residents of Colombo were sampled to determine their willingness to contribute to a trust fund to compensate farmers for elephant damage and thereby support the conservation of elephants in Sri Lanka. The results were then extrapolated (using the simple transfer method) to the entire urban population of Sri Lanka and compared to the economic loss experienced by farmers as a result of damage caused by elephants. It is found that the (estimated) stated willingness of urban Sri Lankan households is more than double the value of crop losses caused by elephants. Therefore, it is argued that this conservation strategy could result in a social economic gain for Sri Lanka.

In addition, the relative importance of different stated reasons of Sri Lankan urban and farm households for wanting to conserve elephants are investigated. They are found to differ significantly. It is discovered that urban residents place much greater weight on the non-use values of elephants than do farm households as reasons for conserving elephants. Furthermore, farm households tend to favour a reduction in elephant populations whereas city dwellers do not. Therefore, there is some conflict between the values of urban and rural residents. Increasing urbanization may result in increased conflict in conservation values held by urban and rural residents.

Compared to elephants and sea turtles, Australia's tree-kangaroos are poorly known. Support for the conservation and for the survival of treekangaroos is assessed in Chapter 5 using two serial surveys of a sample of Brisbane residents. Survey I was conducted prior to providing information to respondents about tree-kangaroos and a set of other wildlife species. Survey II was completed after the provision of this information. The results from Survey I confirmed that respondents were poorly informed about tree-kangaroos. Even so, 95 per cent of respondents said that they are in favour of the survival of tree-kangaroos. Several respondents com- 
mented that 'we have a responsibility to protect all species'. The effect of information provision on stated willingness to pay for the conservation of tree-kangaroos is assessed by comparing the results obtained from Survey II with those from Survey I. Depending on the basis of this comparison, the sum allocated for the conservation of the tree-kangaroo increased when extra information was provided about it and other species.

Nevertheless, providing extra information about the characteristics of a wild species does not necessarily result in an increase in the stated willingness to pay for its conservation, as is clear from the results reported in Chapter 11. Chapters 11 and 12 identify the presence of general relationships between the provision of information about the attributes of wild species and the stated willingness of individuals to pay for the conservation of each. It is also found that non-use values account for the major portion of willingness to pay for the conservation of the tree-kangaroo. ${ }^{4}$

Support for the conservation of the mahogany glider is investigated in Chapter 6. Like the species of tree-kangaroos, this is a poorly known species. It is, however, in greater danger of extinction than Australia's tree-kangaroos, is rare, and now only has a very limited range in North Queensland. Non-use values account for virtually all of its economic value.

Within its geographical range, protected areas are currently inadequate to conserve a minimum viable population of this species. However, an area of state land is identified that, if protected (added to existing protected land), would be sufficient to conserve a minimum viable population of this species. The cost of protecting this land is estimated by taking into account the price of comparable land used for commercial purposes. This is assumed to be the opportunity cost of protecting this land. The willingness of Australians (and Queenslanders) to pay to conserve this species is estimated by drawing on the results from a survey of a sample of Brisbane residents. It is found that the social benefit of conserving the mahogany glider by increasing the protected area of its habitat (in the specific way identified) substantially exceeds the cost of doing this.

In addition, the results (reported in this chapter) from three serial surveys of a sample of Brisbane residents provide some support for patterns of dynamic changes in the stated willingness to pay for the conservation of species. Such patterns were proposed in Tisdell (2007) and in Tisdell et al. (2008), and are also discussed in Chapter 2. Three different values for stated willingness to pay emerge in each of the three serial surveys. Consequently, it is not clear which of these values should be used for the purpose of environmental valuation.

The main purpose of Chapter 7 is to explore the extent to which public funding for the conservation of wild species reflects the preferences of members of the public for such funding. The koala (a well-known, 
well-liked, humanoid species) and the northern hairy-nosed wombat (a less well-known, less-liked and less human-like species) are selected for this investigation. The latter species is classified by the IUCN as critically endangered, whereas the survival of the koala is classified as being of least concern.

It is discovered that while a sample of the Brisbane public stated that it is willing to pay more for the conservation of the northern hairy-nosed wombat than for the conservation of the koala, public funding of the conservation of the koala exceeds that for the northern hairy-nosed wombat. It is hypothesized that the latter may occur because the koala is a mixed good, whereas the northern hairy-nosed wombat is a pure public good. Reasons are suggested why the different nature of these 'commodities' results in biases in conservation funding.

In addition, factors influencing individuals' stated willingness to pay for the conservation of these two species are explored. In this particular case, the relative endangerment of the two species rather than differences in their likeability appears to have the greatest impact on the relative amounts individuals are willing to pay for the conservation of each. More general analysis in Chapters 11 and 12 confirms that the endangerment of species rather than their likeability is a more important influence on stated willingness to pay for the conservation of species.

A further feature of Chapter 7 is that it identifies cultural factors as having an important influence on support for the conservation of the different wildlife species. This theme is developed further in Chapter 10 when support for the conservation of different species of reptiles is assessed.

Whereas Chapters 4-7 are concerned with public attitudes to conserving individual species of wild mammals and the economics of their conservation, Chapters 8 and 9 concentrate on the conservation of two species of reptiles, namely the hawksbill turtle and the saltwater crocodile. The hawksbill turtle is classified by the IUCN as critically endangered, whereas the saltwater crocodile is considered to be secure in Australia. It is shown in Chapter 8 that the hawksbill turtle is well liked by members of the Australian public, in contrast to the mostly disliked saltwater crocodile.

Based on responses from a sample of the Australian public, Chapters 8 and 9 respectively identify variables influencing the public's support for the conservation of hawksbill turtles and saltwater crocodiles. These chapters report on the public's knowledge of these species, how much they are liked, the stated willingness of those surveyed to pay for their conservation and the extent to which their survival is supported. Changes occurring in these variables as a result of the provision of information about these species and other wildlife species are also studied. Particular attention is given to the level of public support for the commercial use of these species. This is 
done in view of the fact that the Convention on Biological Diversity supports the view that the use of wild species can contribute to their conservation. On the whole, surveyed members of the Australian public opposed the harvesting of hawksbill turtles but strongly supported the harvesting of saltwater crocodiles.

Wild stocks of saltwater crocodiles are in fact harvested in Australia. The harvest consists mainly of their eggs and hatchlings. This harvest is utilized on crocodile farms primarily for the production of crocodile skins. The managed sustainable commercial use of this wild species in Australia has played an important role in the recovery of Australia's population of wild saltwater crocodiles. Prior to changed policies, the saltwater crocodile was nearly driven to extinction in Australia by the early 1970s due to excessive hunting.

Factors affecting the sustainable use of saltwater crocodiles in Australia (especially the Northern Territory) are given particular attention in Chapter 9. The role of economic, ecological and social factors in ensuring the continued sustainable use of saltwater crocodiles is explored. In doing this, the future of the Australian crocodile industry is examined within the global context of the crocodile industry.

\subsection{VALUES AND THE CONSERVATION AND USE OF SEVERAL WILD SPECIES: AN OVERVIEW OF PART III}

The research net is cast wider in Part III than in Part II. Part III concentrates on assessing relative support of members of the public for conserving different wild species when several must be considered for support simultaneously. Furthermore, it gives greater attention to the influence of social factors on support for the conservation of wild species than does Part II. Differences in the level of the public's support for the use of a variety of wildlife species, including their use by Indigenous communities, are also investigated in Part III.

Chapter 10 examines the relative support of members of the public for conserving each of five species of reptiles: two species of turtles, two species of crocodile and a snake species. Similar research procedures (relying on surveys and sampling) to those used in Chapters 8 and 9 are adopted. Relying on the responses of those sampled, the following are investigated:

- knowledge of each of the species;

- their relative likeability; 
- the extent of support for the survival of each;

- the stated willingness of respondents to pay for the conservation of each of the focal species; and

- the level of support for the sustainable commercial harvesting of each of these species.

The impacts on these variables when extra information is provided to those sampled about the attributes of each of these reptile species (including their conservation status) are studied. Influences of social factors (for example, religious and cultural traditions) on human valuation and attitudes towards different reptile species are given special consideration in this chapter. Furthermore, important alterations are identified in human valuations and attitudes towards species, which occur as societies develop.

It is revealed (from the sampling) that strong support exists for survival of all the reptile species assessed, including those that are least liked, such as the saltwater crocodile and taipan snake. However, there is stronger support for the survival of those species that are most liked, in this case, the turtle species. Strong evidence is found that the public values turtles much more highly than other reptiles: a bipolar distribution of valuation of reptile species seems to exist. To some extent, this undermines the phylogenetic similarity principle - the principle that humans prefer species that belong to phyla closer to their own. This relationship is examined in Chapters 13 and 14. However, the bipolar distribution of the extent to which reptile species are liked may not be as marked as appears to be so from Chapter 10. This is because the assessment does not include some types of reptiles (for example, lizards and skinks). Although it would have been desirable to include these in the valuation, this would have overloaded respondents.

The knowledge that humans have about the attributes of commodities has an important influence on their valuation of these and, consequently, on their behaviour involving these commodities. Therefore, the knowledge possessed by individuals about wild species is studied in Chapter 11. Particular attention is given to how changes in knowledge of the attributes of wild species alter the support of individuals for their survival and conservation. Several important relationships are detected. These include the following:

- Other things being held constant, increased knowledge about the attributes of wild species in a given set tends to increase the inequality in the amounts individuals say that they are willing to pay to conserve each of the species in the set.

- This increased inequality tends to be most marked for those species that were initially the least well known. 
- The average stated WTP for the conservation of the initially least well-known species in the given set tends to rise (as knowledge of all species in the set increases). This is likely to occur at the expense of those species in the set that were initially best known.

- Circumstantial evidence is found that increased knowledge about the conservation status of a wild species has a larger impact on the WTP for its conservation than does information that changes the extent to which the species is liked.

Policy implications of these results are outlined and the last-mentioned hypothesis is investigated in detail in Chapter 12.

Using survey data, Chapter 12 supports the view that although the extent to which a species is liked has a positive influence on the stated willingness of individuals to pay for its conservation, the dominant influence is the extent to which the survival of species is believed to be endangered. This result differs from that of Loomis and White (1996), Metrick and Weitzman (1996) and Richardson and Loomis (2009), but accords with that of Tkac (1998). Policy consequences of this finding are outlined.

Chapters 13 and 14 investigate (from different angles) the applicability of the similarity principle, that is, the principle that individuals find species that are more human-like to be more appealing or likeable than other species. Consequently, more human-like species are favoured for conservation and survival. This implies that species belonging to higher-order phyla (for example, mammals) are preferenced to those belonging to lowerorder phyla (for example, reptiles). Therefore, one would expect species of mammals to be preferred to birds and birds to be preferred to reptiles, with relative support for the conservation of these species following the same pattern.

Using survey data, the extent to which willingness to pay for the conservation of wild species belonging to different classes (phyla) is studied in Chapter 13. It is found that WTP for the conservation of species does not exactly follow the pattern postulated by the similarity principle. For example, not all reptiles (for instance, turtle species) are less liked than all species of mammals and birds. Furthermore, as discovered in Chapter 12, likeability is not the dominant influence on stated WTP for conservation of individual species. Rather, the extent to which they are endangered is more important.

When support for the survival of different wild species is investigated (as is done in Chapter 14), there is stronger support for the similarity principle, even though it does not hold strictly. When only a limited number of species can be chosen for survival, the proportion of higher-order species chosen tends to exceed those of a lower order. For example, the proportion 
of mammal species favoured for survival exceeds the proportion of bird species, which in turn exceeds the proportion of reptile species selected for survival. This relationship is supported by survey data analysed in Chapter 14. It is emphasized that variations in the WTP for the conservation of different wild species does not necessarily reflect differences in the degree of support for their survival.

The United Nations Convention on Biological Diversity supports the notion that the sustainable use of wild species can provide an incentive for their conservation and as a result, can help to maintain biodiversity. However, if public support for such policies is lacking, this is a political obstacle to their implementation. Therefore, Chapter 15 (using responses from a sample survey) investigates the extent to which members of the public support the sustainable use of wild species. The results suggest that the public only supports the harvesting of those wild species that are abundant and not in any danger of extinction. Furthermore, the larger the amount individuals state they are willing to pay for the conservation of a species, the lower is their support for its sustainable (commercial) harvesting. The likeability of species has little influence on support (or otherwise) for the commercial harvesting of a species.

It is also revealed that those respondents who claim to be very conservation-minded are less likely than other respondents to support the commercial harvesting of wild species. In general, the responses of those sampled suggest that they are sceptical about sustainable use being an effective policy for conserving endangered wild species. This is also apparent from the results reported in Chapter 16. In this chapter it is reported that the majority of respondents to a survey opposed the subsistence use of endangered wildlife species by Indigenous Australians.

Chapter 16 explores the attitudes of a sample of the Australian public to the use (including both subsistence and commercial use) of wildlife species by Indigenous Australians. It begins by highlighting the socio-economic disadvantages of Indigenous Australians, especially those in remote areas where their disadvantage is greatest. One of the reasons why this is the case is that economic opportunities for Indigenous Australians are quite limited in such areas. Nevertheless, some remote areas are endowed with wildlife resources that could be used for commercial economic gain by local Indigenous communities. The scope for this is assessed along with the role played by such use in biodiversity conservation. The commercial use of wildlife species by the Aboriginal community in Maningrida (located in Arnhem Land in the Northern Territory) is selected as a case study. It is found (for the economic reasons specified in Chapter 16), that Indigenous commercial enterprises located in remote areas and relying on the consumptive (extractive) use of wildlife, have limited capacity to ameliorate 
the economic disadvantages experienced by remote Indigenous communities. Furthermore, in Australia's case, it is not clear that these commercial enterprises make a significant contribution to biodiversity conservation. In addition, surveyed members of the Australian public did not support the view that Indigenous Australians, if left to their own devices, would conserve wild biodiversity, for instance on their own lands. Reasons for this are discussed in Chapter 16. On the whole, those surveyed were unsympathetic to the type of conservation policies proposed by Ostrom (1990).

\subsection{CONCLUDING COMMENTS}

The economics of biodiversity conservation is a complex subject requiring consideration of both social and ecological factors. Its complexities and challenges need to be faced head on rather than ignored. For instance, estimating the value of biodiversity conservation is far from straightforward. For one thing, it can be valued from different points of view. For example, there can be variations in the weight placed on ecocentric values and on anthropocentric ones.

If the economic approach is adopted based on the assumption that the value of conserving different species depends on what individuals are willing to pay for their conservation, several problems arise in eliciting these preferences. For example, they may not be stable or very stable, and they usually vary with the information that individuals have about different species and other commodities. In the long term, social influences on these values also alter. If such influences are recognized, allowances can be made for them in the policy applications and the conclusions drawn from the economic analysis of the conservation of wild species can be modified. This is the approach adopted in this book.

Of course, the economics of conserving wild species does not depend solely on how much they are valued, but it is an important component. The cost (opportunity cost) of their conservation must also be taken into account, as is done in Chapters 4 and 6 in this book.

In this study, as in much of my previous work, the consequences for individual preferences and behaviours of uncertainty and of changes in the amount of information or knowledge possessed by individuals is a central concern. This central concern reflects my view that bounded rationality is a pervasive major influence on behaviour (Tisdell, 1996, 2013). This represents an important departure from the strong rationality assumptions that underlie neoclassical economies. This departure also suggests that worthwhile advances in economic thought are likely to result from the empirical study of economic behaviours and accompanying psychological influences 
on these. The use of experimental methods is an important, but not exclusive, part of such an approach. All of the research results reported in Parts II and III of this book are based on empirical data and Chapters 5-15 report the behavioural consequences of experimentally altering the information available to individuals. The questionnaires and data used for this purpose are available in Tisdell and Wilson (2014) with accompanying explanation.

Although introspection and Aristotelian logic has helped to advance economic theory, their scope to continue to do so is limited compared to the alternative empirical and experimental approaches indicated above. Furthermore, there is no good reason why economic studies should be confined to the narrow boundaries of the economic discipline. In a study such as this one, a wider view is essential. For example, some account must be taken of ecological considerations and sociological factors. Therefore, an interdisciplinary approach is adopted wherever it is considered necessary to better understand the nature of things.

\section{NOTES}

1. See, for example, Leakey and Lewin (1996), Wilson (2003) and Anon (2013a, 2013b).

2. It should not, however, be concluded that intangible attributes of wildlife have no value in less developed communities.

3. There is some additional discussion of this topic in Tisdell (2005, pp. 9-10).

4. Nevertheless, Australian tree-kangaroos have limited non-consumptive use value for tourism (Tisdell and Wilson, 2012, Chapter 15). A few are also hunted by Australian Aborigines for subsistence purposes but such hunting is declining and is no longer considered to be a threat to their survival (Martin, 2005). This contrasts with the hunting of species of tree-kangaroos in New Guinea (ibid.). These observations are consistent with the above hypothesis that the consumptive use value of wild species tends to decline with economic development.

\section{REFERENCES}

Anon (2013a), 'Extinction event', Wikipedia, accessed 21 November 2013 at http:// en.wikipedia.org/wiki/Extinction_event.

Anon (2013b), 'Holocene, extinction', Wikipedia, accessed 21 November 2013 at http://en.wikipedia.org/w/index.php?title $=$ Holocene_extinction.

Anon (2013c), 'Subjective theory of value', Wikipedia, accessed 21 November 2013 at http://en.wikipedia.org/w/index.php?title=Subjective_theory_of_value.

IUCN-UNEP-WWF (1991), Caring for the World: A Strategy for Sustainable Living, Gland, Switzerland: World Conservation Union.

Leakey, R. and R. Lewin (1996), The Sixth Extinction: Patterns of Life and the Future of Humankind, New York: Anchor Books.

Leopold, A. (1933), Game Management, New York: Scribner. 
Leopold, A. (1966), A Sand County Almanac: With Other Essays on Conservation from Round River, New York: Oxford University Press.

Loomis, J.B. and D.S. White (1996), 'Economic benefits of rare and endangered species: summary and meta-analysis', Ecological Economics, 18(3), 197-206.

Martin, R. (2005), Tree-kangaroos of Australia and New Guinea, Collingwood, VIC, Australia: CSIRO Publishing.

Metrick, A. and M.L. Weitzman (1996), 'Patterns of behavior in endangered species preservation', Land Economics, 72(1), 1-16.

Ostrom, E. (1990), Governing the Commons: The Evolution of Institutions for Collective Action, New York: Cambridge University Press.

Richardson, J.I. and J.B. Loomis (2009), 'The total economic value of threatened endangered and rare species: an updated meta-analysis', Ecological Economics, 68(5), 1535-48.

Robbins, L. (1937), An Essay on the Nature and Significance of Economic Science, London: Macmillan.

Sagoff, M. (1996), 'On the value of endangered and other species', Environmental Management, 20(6), 871-911.

Tisdell, C.A. (1996), Bounded Rationality and Economic Evolution, Cheltenham, UK and Brookfield, VT, USA: Edward Elgar Publishing.

Tisdell, C.A. (2005), Economics of Environmental Conservation, 2nd edition, Cheltenham, UK and Northampton, MA, USA: Edward Elgar Publishing.

Tisdell, C.A. (2007), 'Knowledge and the valuation of public goods and experential commodities: information provision and acquisition', Global Business and Economics Review, 9(2/3), 170-82.

Tisdell, C.A. (2013), Competition, Diversity and Economic Performance. Processes, Complexities and Ecological Similarities, Cheltenham, UK and Northampton, MA, USA: Edward Elgar Publishing.

Tisdell, C.A. and C. Wilson (2012), Nature-based Tourism and Conservation: New Economic Insights and Case Studies, Cheltenham, UK and Northampton, MA, USA: Edward Elgar Publishing.

Tisdell, C.A. and C. Wilson (2014), 'Three questionnaires used in evaluating the economics of conserving Australia's tropical wildlife species and the procedures adopted', Economics, Ecology and the Environment, Working Paper No. 191, St Lucia, QLD: School of Economics, The University of Queensland.

Tisdell, C.A., C. Wilson and H. Swarna Nantha (2008), 'Contingent valuation as a dynamic process', Journal of Socio-Economics, 37(4), 1443-58.

Tkac, J. (1998), 'The effects on information on willingness-to-pay values of endangered species', American Journal of Agricultural Economics, 80(5), 1214-20.

United Nations (1993), Convention on Biological Diversity - UN Documents, accessed 24 March 2014 at www.un-documents.net/cbd.

Wilson, E.O. (2003), The Future of Life, New York: Vintage Books. 